\title{
A COMPREENSÃO DOS ACADÊMICOS DO CURSO DE CIÊNCIAS CONTÁBEIS DAS INFORMAÇÕES CONTIDAS NO BALANÇO ORÇAMENTÁRIO
}

\author{
Synthia Luyse Bennert ${ }^{1}$ \\ Magno Alves Ribeiro ${ }^{2}$
}

\section{RESUMO}

Este estudo objetiva conhecer a compreensão que os acadêmicos do curso de Ciências Contábeis têm do Balanço Orçamentário, demonstrativo este que apresenta quais as receitas e despesas previstas para o exercício que ele esta sendo elaborado e evidencia a maneira como os recursos públicos estão sendo investidos. A pesquisa foi desenvolvida através de estudos bibliográficos e levantamento de dados, onde foi aplicado, um questionário composto de quatorze questões, acompanhado do Balanço Orçamentário, aos acadêmicos do primeiro ao quarto semestre do curso de Ciências Contábeis. Realizou-se a contagem dos dados e análise dos mesmos por meio de tabelas comparativas, que demonstraram que a maior parte dos pesquisados identificaram corretamente os valores contidos na demonstração pública do Balanço Orçamentário.

Palavras Chave: Contabilidade Pública. Controle Social. Compreensibilidade.

\section{1. - Introdução}

A gestão fiscal responsável requer planejamento e transparência nas ações das entidades de caráter público. Para isso a Lei de Responsabilidade Fiscal estabelece que as demonstrações contábeis e fiscais sejam amplamente divulgadas.

O Balanço Orçamentário é uma demonstração que evidência as receitas que a administração pública estima arrecadar e também as despesas que estão vinculadas aos recebimentos. Outra função que se atribui é a de apresentar como foi executado na realidade o orçamento previsto. (SILVA, 2004)

Considerando a função que é atribuída ao Balanço Orçamentário a questão que se pretende sanar com este estudo é: Qual a compreensão que os acadêmicos do primeiro ao quarto semestre do curso de Ciências Contábeis da UNEMAT - Campus de Tangará de Serra - MT tem do Balanço Orçamentário? Considerando a hipótese que os acadêmicos do curso de Ciências Contábeis da UNEMAT compreendem o Balanço Orçamentário.

Este estudo tem como principal foco a compreensão das informações produzidas pela contabilidade governamental. Tendo como objetivo geral conhecer a compreensão que os

\footnotetext{
${ }^{1}$ Acadêmica do Curso de Ciências Contábeis, da Universidade do Estado de Mato Grosso Campus Universitário de Tangará da Serra - UNEMAT, synthiabennert@ hotmail.com;

${ }^{2}$ Prof. Mestre do Departamento de Ciências Contábeis, da Universidade do Estado de Mato Grosso Campus Universitário de Tangará da Serra - UNEMAT, magnoalves@unemat.br.
} 
acadêmicos do curso de Ciências Contábeis do Campus da UNEMAT - Tangará da Serra tem das informações contidas no Balanço Orçamentário. O objetivo geral foi desdobrado em objetivos específicos, onde investigou-se as normas que regem a administração pública no que diz respeito à questão da transparência, através de referências bibliográficas e verificação do nível de entendimento que os acadêmicos do curso de ciências contábeis da Unemat têm do Balanço Orçamentário divulgado pela Prefeitura Municipal de Tangará da Serra - MT.

De acordo com a Controladoria Geral da União (CGU, 2009) é dever da prefeitura informar a sociedade de como o dinheiro público esta sendo gasto, e para isso é necessário que a população entenda o conteúdo dos demonstrativos governamentais. Logo o tema abordado é: A compreensão dos acadêmicos do curso de Ciências Contábeis acerca do Balanço Orçamentário.

Deste modo, considera-se o tema abordado relevante, pois para que haja a prática da transparência e da cidadania, é imprescindível que o contribuinte consiga ter clareza do que esta sendo realizado com o dinheiro público. Pois é através deste conhecimento que o cidadão sabe como os recursos arrecadados estão sendo aplicados, podendo assim, definir se as necessidades da comunidade são atendidas. Portanto, a cidadania começa a ser exercitada a partir do momento em que se pode conhecer e participar das práticas políticas da comunidade em que se está inserido, e para isso é fundamental a busca por informações a respeito dos recursos públicos.

\section{Referencial Teórico}

\section{1 - Orçamento Público}

Orçamento Público é o ato de se planejar antecipadamente as finanças públicas, prevendo as receitas e despesas do exercício, é efetuado pelo poder executivo, que o encaminha ao legislativo para sua efetiva aprovação, se tornando assim lei, a Lei do Orçamento. (SANTOS, 2001)

A lei do orçamento deverá conter, de acordo com a lei $\mathrm{n}^{\circ} .4320$, de 17 de março de 1964, em seu art. 2:

Art. $2^{\circ}[\ldots]$ a discriminação da receita e despesa de forma a evidenciar a política econômica financeira e o programa de trabalho do Governo, obedecidos os princípios de unidade, universalidade e anualidade.

O orçamento deve expressar as receitas e as despesas de forma verdadeira, ou seja, apresentar confiabilidade nas previsões orçadas no início do exercício, pois deste modo a execução também poderá ser correta e clara. 
Conforme determina a Constituição Federal de 1988 o executivo deverá estabelecer em forma de lei o Plano Plurianual, a Lei de Diretrizes Orçamentárias e a Lei Orçamentária Anual (BRASIL, 1988). O Plano Plurianual (PPA) é um plano de governo na qual se identifica os objetivos e metas que a administração pública pretende atingir no período de seu mandato, é elaborado no primeiro ano de governo e irá vigorar até o primeiro ano de mandato do governo seguinte, para que haja assim um planejamento contínuo. As outras matérias orçamentárias serão elaboradas todas em consonância com o PPA. A Lei de Diretrizes Orçamentárias (LDO) visa definir as prioridades da administração pública e também orientar na elaboração do orçamento anual. De acordo com o art. $4^{\circ}$, inciso $\mathrm{I}$, da Lei de Responsabilidade Fiscal (LRF) a LDO deverá dispor sobre o equilíbrio entre receitas e despesas, formas de limitação de empenhos, normas relativas ao controle de custos, a avaliação de resultados de programas, condições e exigências para a realização de transferências. A Lei Orçamentária Anual (LOA) deverá ser elaborada em concordância com a PPA e a LDO, será encaminhada ao legislativo, através do executivo municipal a cada exercício fiscal.

Deverá apresentar em determinação da Constituição Federal de 1988, o seu art. 165, § $5^{\circ}:$

\footnotetext{
§ 5o A lei orçamentária anual compreenderá:

I - o orçamento fiscal referente aos Poderes da União, seus fundos, órgãos e entidades da administração direta e indireta, inclusive fundações instituídas e mantidas pelo poder público;

II - o orçamento de investimento das empresas em que a União, direta ou indiretamente, detenha a maioria do capital social com direito a voto;

III - o orçamento da seguridade social, abrangendo todas as entidades e órgãos a ela vinculados, da administração direta ou indireta, bem como os fundos e fundações instituídos e mantidos pelo poder público.
}

A Lei Orçamentária Anual dispõe sobre as receitas previstas para o exercício financeiro e com base nelas autoriza-se as despesas, nenhuma despesa poderá ser realizada sem estar prevista no orçamento. Porém, se houver necessidade o executivo encaminhará um projeto de lei ao legislativo com pedido de abertura de créditos suplementares. Trinta dias após o final do bimestre o executivo necessita entregar relatório referente à execução do orçamento previsto. (BRASIL, 1988). Relatório que será utilizado como instrumento de fiscalização dos atos do governo.

O orçamento é fundamental para o controle social das contas públicas, pois é através dele que o governo expressa seus planos de administração, possibilitando assim aos contribuintes conhecer o que se planeja para a comunidade e também o que esta se fazendo para atingir tal meta (ANDRADE, 2002). O método utilizado para manter o controle do Revista UNEMAT de Contabilidade, ano 1, n.1, jan./jun. 2012. 
planejamento e da execução orçamentária é o Balanço Orçamentário que é elaborado ao final do exercício. (MIRANDA et al., 2008)

\subsection{1 - Balanço Orçamentário}

O Balanço Orçamentário é um demonstrativo que apresenta a previsão em termos de arrecadação e aplicação de recursos, em programas e projetos governamentais, e efetivamente as ações do governo, ou seja, o que se arrecadou e como se investiu esses recursos na realidade, é o confronto das receitas e despesas previstas com as realizadas (BRASIL, 1964).

Receitas são recursos arrecadados através da cobrança de impostos, taxas, tributos e também com repasses de outros órgãos, como no caso dos municípios podem ser repasses da união ou do estado. A lei 4320/64 determina que receitas são os recebimentos do ente público (BRASIL, 1964). Essas receitas são classificadas de acordo com sua categoria econômica e dessa se qualificam quanto a sua fonte, origem e vinculação. Por categoria econômica serão receitas correntes ou receitas de capital. Receitas correntes são os recebimentos que ocorrem através da transferência de valores de pessoas de direito público e privado e que se destinam a atender as necessidades meio e fim do ente federativo.

As fontes das Receitas Correntes podem ser divididas em Receitas Tributárias, se da através da arrecadação de impostos taxas e contribuições de melhoria, Receitas de Contribuições, são recursos derivados de contribuições sociais, intervenção no domínio público e interesse das categorias profissionais ou econômicas, Receita Patrimonial, são rendimentos de aplicação de ativos permanentes, Receita Agropecuária, adquiridas através da atividade de exploração agropecuárias, Transferências Correntes, são recursos recebidos de outros entes com o objetivo de ser aplicado em despesas correntes, entre outras (BRASIL, 2007). A origem de cada receita esta ligada a sua vinculação, de onde surgiu. (GIACOMONI, 1998; SILVA, 2004; MACHADO JR; REIS, 2003).

Silva (2004, p.112) conceitua receita de capital como sendo:

[...] as derivadas da obtenção de recursos mediante a constituição de dividas (operações de crédito), da alienação de bens do ativo permanente (alienação de bens), do recebimento de direitos (amortização de empréstimos e financiamentos concedidos) [...]

Receitas de Capital são as que têm origem de atividades não operacionais do estado, como por exemplo, a venda de bens da instituição pública, a concessão de empréstimos a outros entes. Para Machado Jr. e Reis (2003) receitas de capital são recursos que serão destinados à formação de um bem de capital, como asfalto, escolas, creches e também para 
manutenção das atividades do estado. A grande finalidade do recolhimento desses recursos é a sustentação da atividade pública. Cada receita tem sua destinação, ou seja, pagamento das despesas, necessárias para o funcionamento da máquina pública, e também investimentos.

Conceitualmente despesas são todos os pagamentos realizados ou assumidos pela administração pública. Podendo ser dividas em despesas correntes e de capital. Despesas correntes são que não proporcionam retorno à instituição, mas sim a diminuição do seu patrimônio; já as despesas de Capital são as que resultam no acréscimo do patrimônio do estado. (SILVA, 2004)

O documento criado para o controle da execução orçamentária é o Balanço Orçamentário, segundo Giacometti, Cavalcante e Ventura (2000, apud MIRANDA et al, 2008), pois fornece dados sobre as receitas e despesas previstas no orçamento e as receitas e despesas executadas. Portanto, o Balanço Orçamentário possibilita que o orçamento seja verificado e analisado. $\mathrm{O}$ contribuinte tem direito e deseja ter informação sobre como o dinheiro público esta sendo gasto, e para isso o balanço orçamentário deve ser apresentado de forma clara, para que se tenha exata noção do que esta ocorrendo na administração pública (SILVA, 2004).

\title{
2.1.2 - Princípios Orçamentários da Publicidade e Clareza
}

Os princípios orçamentários são regras que tem o objetivo de regulamentar a elaboração e a execução do orçamento, para que o este seja confiável, e assim possa ser usado como instrumento de fiscalização dos atos públicos. (GIACOMONI, 1998). Já o princípio da publicidade tem como objetivo principal estabelecer a ampla divulgação das contas públicas.

$\mathrm{O}$ art. 37 , em seu $\S 1^{\circ}$, da $\mathrm{CF} / 88$ cita a publicidade como princípio da administração pública:

\begin{abstract}
Art. 37. A administração pública direta e indireta de qualquer dos Poderes da União, dos Estados, do Distrito Federal e dos Municípios obedecerá aos princípios de legalidade, impessoalidade, moralidade, publicidade e eficiência e, também, ao seguinte: (EC no 18/98, EC no 19/98, EC no 20/98, EC no 34/2001, EC no 41/2003, EC no 42/2003 e EC no 47/2005)...]

§ 1o A publicidade dos atos, programas, obras, serviços e campanhas dos órgãos públicos deverá ter caráter educativo, informativo ou de orientação social, dela não podendo constar nomes, símbolos ou imagens que caracterizem promoção pessoal de autoridades ou servidores públicos.
\end{abstract}

Este princípio deixa claro que os órgãos públicos devem informar a população sobre como estão sendo distribuídos os recursos arrecadados pela instituição, porém o que ocorre 
realmente é que as demonstrações são divulgadas apenas pela obrigatoriedade e não pelo interesse em informar o cidadão. Para complementar o princípio da publicidade tem-se Princípio da Clareza, que segundo Giacomoni (1998) determina que o orçamento seja divulgado em uma linguagem clara e compreensível, pelos usuários da informação. Este incita o estado a tornar suas demonstrações acessíveis ao cidadão, que é o principal interessado nas informações contidas nestes demonstrativos. Para Piscitelli (2004, p. 49) os demonstrativos devem ser "[...] razoavelmente compreensíveis e tornar acessível o detalhamento dos dados e informações divulgados, de forma clara - princípio da clareza -, pois só assim o cidadão terá condições de exercer o controle social".

\section{2 - Transparência e controle social do Orçamento}

A prática da transparência e do controle social possibilita que atos de corrupção e desvio de recursos públicos sejam coibidos, uma vez que haja fiscalização por parte do cidadão há uma maior dificuldade em se desviar recursos sem que tal ato seja percebido (RIBEIRO, 2008).

"A transparência pressupõe três elementos ou dimensões: a publicidade, a compreensibilidade e a utilidade para decisões. Cada elemento complementa e interage com os outros para que a transparência seja plenamente propiciada" (PLATT NETO et al. 2005, p.11). O conceito de transparência tem maior amplitude que o de publicidade, pois publicidade diz respeito a apenas divulgação e transparência se refere à compreensibilidade. A Lei de Responsabilidade Fiscal - LRF estabelece normas para que a transparência seja praticada pelos governos, e assim a população possa exercer o controle social, ou seja, a democracia em si. A redação da LRF, nos arts. 48 e 49 estabelecem regras de transparência, que determinam que seja dada ampla divulgação aos instrumentos de gestão fiscal, através de meios eletrônicos de acesso público, também determina incentivar a participação popular no processo orçamentário, acompanhamento em tempo real da execução orçamentária e adoção de sistema integrado da administração financeira e controle. Outra exigência que se faz é que as contas estejam disponíveis no poder legislativo e no órgão que as elabora durante todo o exercício. (BRASIL, 2000)

O poder público além de incentivar a população a participar do processo orçamentário, deve também manter totalmente disponível qualquer informação que o contribuinte almeje ter, para que assim possa ser possível a prática de controle sobre a gestão pública.

O Controle Social ou accountability, de acordo com a CGU (2010, p. 16): 
[...] pode ser entendido como a participação do cidadão na gestão pública, na fiscalização, no monitoramento e no controle das ações da Administração Pública. Trata-se de importante mecanismo de prevenção da corrupção e de fortalecimento da cidadania.

Deste modo, a prática do controle social é de extrema importância para o exercício da cidadania, pois, através do conhecimento das ações de governo o contribuinte pode auxiliar na fiscalização dos recursos públicos. No Brasil essa participação popular tem papel determinante no combate à corrupção, pois devido à extensão territorial do país os órgãos responsáveis pelo controle das contas públicas, necessitam do apoio da sociedade, para que se garanta que o dinheiro do contribuinte seja bem aplicado e retorne em forma de melhorias para a própria comunidade (CGU, 2010). Porém, o exercício do controle social é prejudicado pelas inúmeras deficiências da informação, que na sua maioria são de caráter estritamente técnico e ainda não são acompanhadas de notas explicativas, resumos ou outras vertentes que seriam para possibilitar seu entendimento.

Segundo Silva (2002, p. 15) “os procedimentos são obscuros e não há publicidade adequada dos atos que afetam diretamente as comunidades. Mesmo quando há publicidade, os mecanismos de atuação existentes não têm sido suficientes para impedir e/ou coibir abusos". Para que haja uma mudança é necessário que essa iniciativa tenha princípio dentro das próprias instituições, pois essas têm o poder de modificar e aperfeiçoar as informações que disponibilizam.

A Secretaria do Tesouro Nacional pronuncia que: "os processos de orçamentação municipal, quando submetidos ao controle social, tornam-se transparentes e voltados para os interesses coletivos da população". (SECRETARIA DO TESOURO NACIONAL, 2006, p.30). O controle social é um instrumento que permite dar transparência ao orçamento, pois leva a sociedade ao conhecimento das ações do poder público. O incentivo ao controle social ainda possibilita avaliar a gestão e direcionar os próximos gestores.

\section{3. - Metodologia}

Para Gil (1995) o método é o caminho que se percorre para se chegar ao objetivo esperado, já o método científico são as técnicas que serão utilizadas para se obter o conhecimento acerca do que se deseja estudar.

Para a realização deste estudo quanto aos seus objetivos foi utilizado o método de pesquisa descritiva, pois se descreve sobre a compreensibilidade dos acadêmicos do curso de Ciências Contábeis das contas públicas da Prefeitura de Tangará da Serra. 
Quanto aos procedimentos, foram utilizados os métodos de pesquisa bibliográfica e levantamento. Conforme Gil (1995) as pesquisas bibliográficas serão aplicadas através de livros, leis e artigos sobre o assunto, que irão dar base para a discussão do problema. Esclarece também que o levantamento se origina por utilizar-se de questionamentos diretos a população na qual se deseja investigar. Portanto neste artigo as ferramentas de levantamento de coleta de dados foram questionários, visando identificar o entendimento que os acadêmicos têm das contas públicas do município Tangará da Serra - MT. Especificamente do balanço orçamentário do município. De acordo com Marconi e Lakatos (2001, p. 107) questionários são compostos por uma série de perguntas que devem ser respondidas por escrito e sem a presença do pesquisador. O questionário utilizado foi apresentado junto com o Balanço Orçamentário, que tem como finalidade básica demonstrar como as receitas e despesas previstas para o exercício financeiro estão sendo executadas pelo governo. Foram aplicadas questões referentes ao conteúdo da demonstração, para possibilitar a análise do entendimento que a amostra selecionada tem do anexo 12 da lei 4320/64.

O questionário dispõe de quatorze perguntas, que são do tipo fechadas, ou seja, com alternativas de múltipla escolha aos respondentes. Estes dados foram coletados no mês de agosto de 2011. A escala utilizada na pesquisa tem um nível de representatividade de 0 a $20 \%$ para nenhum, de 21 a $40 \%$ para pouco, 41 a 60\% para razoável, 61 a $80 \%$ para bom e 81 a $100 \%$ para excelente. A outra escala utilizada foi a escala de diferencial semântico, nesta técnica, se apresenta aos respondentes uma escala de sete pontos, com adjetivos opostos nas extremidades. (GIL, 1999)

Amostra no conceito de Gil (1995, p. 92) é o "subconjunto do universo ou da população, por meio do qual se estabelecem ou se estimam as características desse universo ou população". Na visão de Marconi e Lakatos (2001, p. 108) amostra “[...] constitui uma porção ou parcela, conveniente selecionada do universo (população); é um subconjunto do universo". A amostra utilizada foi selecionada através do método probabilístico de amostragem estratificada não proporcional, delimitando como amostra o grupo de acadêmicos do primeiro ao quarto semestre do curso de ciências contábeis da UNEMAT.

O curso de Ciências Contábeis teve início no campus de Tangará da Serra em cinco de março do ano de mil novecentos e noventa, e tem como objetivo "formar contadores capacitados e qualificados ao exercício profissional, dotados de senso analítico crítico, comprometidos com os valores cristãos de nossa sociedade" (MATO GROSSO, 2008). A cada novo vestibular realizado são disponibilizadas cinqüenta vagas para o curso, portanto a Revista UNEMAT de Contabilidade, ano 1, n.1, jan./jun. 2012. 
amostra esta composta por um número de aproximadamente duzentos alunos, pois a cada vestibular a quantidade de alunos que ingressam no curso é de cinqüenta acadêmicos, de acordo com a Coordenação de Vestibulares e Concursos (COVEST) (MATO GROSSO, 2011). O questionário foi aplicado aos alunos do primeiro ao quarto semestre do curso de Ciências Contábeis, da Universidade do Estado de Mato Grosso - campus de Tangará da Serra. Sendo que do primeiro semestre vinte e quatro (24) alunos responderam ao questionário, do segundo semestre foram vinte e dois (22) respondentes, no terceiro e quarto semestre dezesseis (16) acadêmicos responderam ao questionário em cada turma, totalizando um número de setenta e oito questionados.

Quanto ao gênero dos selecionados (Tabela 1), a amostra esta composta por uma maioria de respondentes do gênero masculino, representando um percentual de 58,97\% dos entrevistados, enquanto $41,03 \%$ dos que responderam são do sexo feminino, conforme Tabela 1 a seguir:

Tabela 1 - Respondentes por Gênero

\begin{tabular}{c|c|c|c}
\hline \hline Gênero & Masculino & Feminino & Total \\
\hline \hline Freqüência & 46 & 32 & 78 \\
\hline \hline$\%$ & $58,97 \%$ & $41,03 \%$ & $100 \%$ \\
\hline \hline
\end{tabular}

Fonte: Dados da Pesquisa. Agosto de 2011

A idade dos respondentes esta concentrada entre dezenove e trinta anos com um percentual representativo de $66,67 \%$ da amostra, o restante esta dividido entre alunos que estão entre dezesseis e dezoito anos, sendo que estes são 30,77\% da amostra o restante da amostra esta entre trinta e um a quarenta e quatro anos representando apenas $2,56 \%$ dos questionados. A escolha da amostra se justifica pelo fato de que estes acadêmicos não têm total noção da matéria pública, mas tem conhecimento geral de contabilidade.

Quanto à abordagem do problema o estudo se classifica como qualitativo, pois os resultados foram analisados e interpretados. (VERGARA, 2004)

"A tabulação é o processo de agrupar e contar os casos que estão nas várias categorias de análise”, conforme Gil (1995, p. 169). A tabulação foi realizada com o auxílio de computador, através de planilhas e os dados foram comparados com a utilização de tabelas.

\section{4 - Análise dos Resultados}


Questões sobre o conhecimento de conceitos da matéria pública foram apresentadas aos respondentes, essas continham perguntas sobre receitas e despesas públicas. Os questionados consideraram ter um conhecimento razoável ou pouca ciência do conceito de receitas públicas (Tabela 2), apresentando porcentagem 37,18\% e 34,62\% da amostra, respectivamente, sendo que destes que consideram ter pouco conhecimento de ganhos públicos a maioria está no primeiro semestre.

Tabela 2 - Respondentes quanto ao conhecimento do Conceito de Receitas Públicas

\begin{tabular}{|c|c|c|c|c|c|c|c|}
\hline & & \multicolumn{4}{|c|}{ Semestres } & \multirow[b]{2}{*}{ Total } & \multirow[b]{2}{*}{$\%$} \\
\hline & & $1^{\circ}$ & $2^{\circ}$ & $3^{\circ}$ & $4^{\circ}$ & & \\
\hline & excelente & 1 & 2 & 0 & 0 & 3 & $3,85 \%$ \\
\hline Conhecimento do conceito & bom & 3 & 0 & 1 & 3 & 7 & $8,97 \%$ \\
\hline \multirow[t]{4}{*}{ de Receitas Públicas } & razoável & 4 & 7 & 10 & 8 & 29 & $37,18 \%$ \\
\hline & pouco & 11 & 8 & 4 & 4 & 27 & $34,62 \%$ \\
\hline & nenhum & 5 & 5 & 1 & 1 & 12 & $15,38 \%$ \\
\hline & Total & 24 & 22 & 16 & 16 & 78 & $100,00 \%$ \\
\hline
\end{tabular}

Fonte: Dados da Pesquisa. Agosto de 2011

Quanto ao conhecimento do conceito de despesas públicas (Tabela 3), observa-se que vinte e oito $(35,90 \%)$ respondentes dizem ter um conhecimento razoável do conceito de despesas públicas, vinte e seis $(33,33 \%)$ tem pouco conhecimento, destes onze (11) estão no primeiro semestre e consideram-se sem nenhum conhecimento treze $(16,67 \%)$ alunos. Dado esse que se justifica pelo fato dos acadêmicos não terem conhecimento dos conceitos públicos. Dos respondentes apenas três $(3,85 \%)$ consideram ter excelente conhecimento da matéria

Tabela 3 - Respondentes quanto ao conhecimento do conceito de Despesas Públicas 


\begin{tabular}{|c|c|c|c|c|c|c|c|}
\hline & & \multicolumn{4}{|c|}{ Semestres } & \multirow[b]{2}{*}{ Total } & \multirow[b]{2}{*}{$\%$} \\
\hline & & $1^{\circ}$ & $2^{\circ}$ & $3^{\circ}$ & $4^{\circ}$ & & \\
\hline \multirow{6}{*}{$\begin{array}{l}\text { Conhecimento do conceito } \\
\text { de Despesas Públicas }\end{array}$} & excelente & 2 & 1 & 0 & 0 & 3 & $3,85 \%$ \\
\hline & bom & 1 & 2 & 3 & 2 & 8 & $10,25 \%$ \\
\hline & razoável & 3 & 9 & 9 & 7 & 28 & $35,90 \%$ \\
\hline & pouco & 11 & 7 & 3 & 5 & 26 & $33,33 \%$ \\
\hline & nenhum & 7 & 3 & 1 & 2 & 13 & $16,67 \%$ \\
\hline & Total & 24 & 22 & 16 & 16 & 78 & $100,00 \%$ \\
\hline
\end{tabular}

Fonte: Dados da Pesquisa. Agosto de 2011

Analisando os dados obtidos, pode-se observar que as questões sobre o conceito de receitas e despesas públicas apresentam porcentagens semelhantes, o que nos leva a considerar que a amostra considera ter o nível de conhecimento médio para os dois questionamentos. A tabela 4 mostra como os acadêmicos analisam o Balanço Orçamentário. Ao apresentar uma questão que tinha uma proposta de analisar o balanço orçamentário, a maior parte considera não saber informar o valor correto da receita tributária, sendo 46,16\% o percentual de respondentes que assinalaram a opção negativa. A resposta obtida com esse questionamento pressupõe a idéia de que os respondentes não compreendem a demonstração, porém outras questões irão esclarecer melhor esse fato.

Tabela 4 - Informar o valor da receita

\begin{tabular}{|c|c|c|c|c|c|c|c|c|}
\hline Pergunta Formulada & $\leftarrow$ Sim & & & & & Nã & $\rightarrow$ & \\
\hline \multirow[t]{2}{*}{ Alternativas } & 1 & 2 & 3 & 4 & 5 & 6 & 7 & Total \\
\hline & 9 & 7 & 6 & 6 & 3 & 11 & 36 & 78 \\
\hline $\begin{array}{l}\text { Sabe informar se o valor da receita } \\
\text { tributária corresponde a } \mathrm{R} \$ \\
18.923 .576,32 \text { ? }\end{array}$ & $11,54 \%$ & $8,97 \%$ & $7,69 \%$ & $7,69 \%$ & $3,85 \%$ & $14,10 \%$ & $46,16 \%$ & $100 \%$ \\
\hline
\end{tabular}

Fonte: Dados da Pesquisa. Agosto de 2011

Foram apresentadas questões que versam sobre valores contidos no balanço orçamentário, que foi anexado ao questionário, questões estas que visam identificar se os Revista UNEMAT de Contabilidade, ano 1, n.1, jan./jun. 2012. 
respondentes têm entendimento do demonstrativo governamental. As perguntas solicitavam que identificassem o valor da receita tributária, o quanto dessa mesma receita foi arrecadado em excesso, de quanto foi a queda de arrecadação da receita patrimonial e também se o balanço apresentou déficit ou superávit.

O resultado apurado demonstrou que a maioria dos entrevistados entendeu a alternativa correta (Tabela 5). Analisando as respostas nota-se em todas as perguntas a opção certa foi a que predominou $62,82 \%$ dos entrevistados acertaram o valor arrecadado de receita tributária, sendo que destes a maior parte dos que assinalaram corretamente estão no primeiro semestre, representando dezesseis entre os quarenta e nove que escolheram a alternativa certa. Acertaram a questão que versa sobre o excesso de arrecadação da receita tributária $61,54 \%$ dos respondentes e 66,67\% identificaram corretamente o valor da queda de arrecadação da receita patrimonial. Após observar o Balanço Orçamentário 78,21\% dos que responderam o questionário puderam constatar que no exercício houve um déficit no orçamento do ente público.

Tabela 5 - Respondentes quanto a compreensão das informações do Balanço Orçamentário

\begin{tabular}{|c|c|c|c|c|c|c|c|c|}
\hline & & & \multicolumn{4}{|c|}{ Acertos por Semestre } & & \\
\hline & Questões & $\begin{array}{l}\text { Alternativa } \\
\text { Correta }\end{array}$ & $\mathbf{1}^{\mathbf{0}}$ & $2^{\circ}$ & $3^{\circ}$ & $4^{\circ}$ & Total & $\%$ \\
\hline $\begin{array}{l}\text { Compreensão } \\
\text { das }\end{array}$ & $\begin{array}{l}\text { Valor da Receita } \\
\text { Tributária Arrecadada }\end{array}$ & $\begin{array}{l}\mathrm{R} \$ \\
17.018 .628,26\end{array}$ & 16 & 13 & 9 & 11 & 49 & $62,82 \%$ \\
\hline informações do & $\begin{array}{l}\text { Valor do excesso de } \\
\text { arrecadação da Receita } \\
\text { Tributária }\end{array}$ & $\mathrm{R} \$ 1.966 .130,08$ & 16 & 13 & 9 & 10 & 48 & $61,54 \%$ \\
\hline Balanço & $\begin{array}{l}\text { Valor da queda de } \\
\text { arrecadação da Receita } \\
\text { Patrimonial }\end{array}$ & $\mathrm{R} \$ 553.075,79$ & 16 & 15 & 9 & 12 & 52 & $66,67 \%$ \\
\hline Orçamentário & $\begin{array}{l}\text { O balanço apresenta } \\
\text { déficit ou superávit }\end{array}$ & déficit & 20 & 17 & 11 & 13 & 61 & \% \\
\hline
\end{tabular}

Fonte: Dados da Pesquisa 
Os respondentes avaliaram os órgãos públicos com relação ao acesso às contas públicas, também sobre a linguagem utilizada no balanço orçamentário. Com relação ao acesso que se tem aos demonstrativos públicos (Tabela 6), 43,59\% (34) consideram que o município dificulta o acesso aos demonstrativos públicos, apenas 5,13\% (4) da amostra acredita que há facilidade em acessar as contas públicas.

Tabela 6 - Respondentes quanto ao acesso as contas públicas

\begin{tabular}{|l|c|c|c|c|c|c|c|c|}
\hline \hline \multicolumn{1}{|c|}{ Pergunta Formulada } & \multicolumn{2}{|l|}{ Facilita } & \multicolumn{3}{|c|}{ Dificulta $\rightarrow$} & Total \\
\hline \hline & $\mathbf{1}$ & $\mathbf{2}$ & $\mathbf{3}$ & $\mathbf{4}$ & $\mathbf{5}$ & $\mathbf{6}$ & $\mathbf{7}$ & \\
\hline $\begin{array}{l}\text { O município facilita o acesso } \\
\text { as contas públicas. }\end{array}$ & 4 & 2 & 7 & 10 & 13 & 8 & 34 & $\mathbf{7 8}$ \\
& $5,13 \%$ & $2,56 \%$ & $8,97 \%$ & $12,82 \%$ & $16,67 \%$ & $10,26 \%$ & $43,59 \%$ & $\mathbf{1 0 0 \%}$ \\
\hline \hline
\end{tabular}

Fonte: Dados da Pesquisa. Agosto de 2011

Avaliando a linguagem utilizada no balanço orçamentário (Tabela 7), foi apresentada aos respondentes uma questão afirmando que a linguagem utilizada é de fácil compreensão, onde indicaram numa escala de 1 a 7 , a sua opinião, indo de concordo a discordo. Os respondentes que consideram a linguagem de difícil entendimento foram 30,77\% (24) da amostra e 20,51\% (16) consideram a linguagem de média compreensibilidade. Sendo que as informações são disponibilizadas pela Lei nº. 4320/64 e Lei nº. 101/2000 (LRF).

Tabela 7 - Respondentes quanto a linguagem utilizada no Balanço Orçamentário

\begin{tabular}{|l|c|c|c|c|c|c|c|c|}
\hline \hline \multicolumn{1}{|c|}{ Pergunta Formulada } & \multicolumn{2}{|c|}{ Concorda } & & \multicolumn{3}{c|}{ Discorda $\rightarrow$} & Total \\
\hline \hline & $\mathbf{1}$ & $\mathbf{2}$ & $\mathbf{3}$ & $\mathbf{4}$ & $\mathbf{5}$ & $\mathbf{6}$ & $\mathbf{7}$ & \\
\hline $\begin{array}{l}\text { Linguagem do balanço } \\
\text { orçamentário. }\end{array}$ & 6 & 9 & 6 & 16 & 9 & 8 & 24 & $\mathbf{7 8}$ \\
\hline \hline
\end{tabular}

Fonte: Dados da Pesquisa. Agosto de 2011

Com base nos dados obtidos na pesquisa nota-se que os acadêmicos não conhecem conceitos de contabilidade governamental, porém tem a compreensibilidade do Balanço Orçamentário, apesar de terem dificuldade de acesso as demonstrações públicas e considerarem a linguagem do Balanço de difícil compreensão. Já em pesquisa realizada por Miranda et. al (2008), com cidadãos de nível educacional acima da média da população 
brasileira, identificou que as informações produzidas pela contabilidade pública, especificamente o Balanço Orçamentário, não são devidamente compreendidas, independente de nível educacional e conhecimento em contabilidade governamental.

\section{5 - Considerações Finais}

O presente estudo investigou qual a compreensão que os acadêmicos do primeiro ao quarto semestre do curso de ciências contábeis da UNEMAT campus de Tangará da Serra tem das informações contidas no Balanço Orçamentário, com a sugestão de hipótese que os acadêmicos do curso de Ciências Contábeis compreendem o Balanço Orçamentário. Os resultados obtidos permitem afirmar que estes acadêmicos compreendem as informações do balanço orçamentário, validando a hipótese sugerida.

Teve como objetivo avaliar a compreensão que os acadêmicos do curso de ciências contábeis têm das demonstrações contábeis públicas, especificamente o balanço orçamentário, que é o meio de divulgação do orçamento do órgão público. Tal questão se mostra importante na medida em que se considera a transparência como um instrumento da gestão pública responsável. O ato da transparência não significa apenas divulgar as demonstrações públicas, mas também torná-las compreensíveis ao cidadão, que é o principal beneficiado pelo controle dos gastos públicos, pois com a participação contribui-se para uma aplicação eficiente dos recursos públicos.

Entre as principais questões abordadas salienta-se que a maioria dos entrevistados considera ter um nível de conhecimento razoável dos conceitos de matérias da contabilidade pública, considerando que os entrevistados apesar de conhecerem os conceitos gerais de contabilidade, não conhecem a matéria pública, que é um texto especifico. Também se discutiu as perspectivas da compreensão dos acadêmicos acerca do Balanço Orçamentário, onde o resultado representa que a maior parte dos entrevistados entende as questões que versam sobre os valores demonstrados.

A limitação que se identifica no estudo é o número de respondentes e também o nível educacional dos mesmos, que não permite que o resultado seja considerado como representativo da população em geral.

Como desdobramento das conclusões encontradas sugere-se que novas pesquisas sejam realizadas com a população em geral, a fim de identificar se estes compreendem o demonstrativo que lhes foi apresentado. Outra sugestão seria verificar se a academia influência nessa compreensão, comparando aos acadêmicos que já cursaram a matéria de 
contabilidade pública. Também pesquisar junto a população uma forma de apresentar os dados para que uma maior parcela da comunidade venha a entendê-los.

\section{6 - Referências Bibliográficas}

ANDRADE, Nilton de Aquino. Contabilidade pública na gestão municipal. São Paulo: Atlas, 2002.

BRASIL, Lei Federal no $\mathbf{n}^{\mathbf{0}} 4320$ de 17 de março de 1964. Estatui Normas Gerais de Direito Financeiro para elaboração e controle dos orçamentos e balanços da União, dos Estados, dos Municípios e do Distrito Federal. Disponível em: <http://www.planalto.gov.br/ccivil_03/Leis/L4320.htm.> Acesso em 30 de abril de 2011.

BRASIL, Constituição da Republica Federativa do Brasil de 5 de outubro de 1988. Brasília: Câmara dos Deputados, 2011. Disponível em:

<http://www2.camara.gov.br/atividadelegislativa/legislacao/Constituicoes_Brasileiras/constit uicao1988.html/constituicaotextoatualizado.pdf.> Acesso em 29 de abril de 2011

BRASIL, Ministério da Fazenda. Secretaria do Tesouro Nacional. Receitas públicas: manual de procedimentos: aplicado à União, Estados, Distrito Federal e Municípios. $4^{\mathrm{a}}$ edição Brasília: Secretaria do Tesouro Nacional, Coordenação-Geral de Contabilidade, 2007. Disponível em: <http://siops.datasus.gov.br/Documentacao/PT_STN-SOF_02-

2007_Manual.pdf> Acesso em 22 de outubro de 2011

BRASIL, Lei Complementar, $\mathbf{n}^{\mathbf{0}} \mathbf{1 0 1}$ de 4 de maio de 2000. Estabelece normas de finanças públicas voltadas para a responsabilidade na gestão fiscal e dá outras providências. Disponível em: <http://www.planalto.gov.br/ccivil_03/Leis/LCP/Lcp101.htm.> Acesso em 29 de abril de 2011.

BRASIL, Secretaria do Tesouro Nacional, Escola de Administração Fazendária.

Experiências Recentes de Controle Social sobre o Processo de Orçamentação Pública Municipal no Brasil. 2006. Disponível em:

<http://www.tesouro.fazenda.gov.br/premio_TN/XIPremio/sistemas/2tosiXIPTN/2premio_tos i.pdf.> Acesso em 01 de maio de 2011.

CONTROLADORIA GERAL DA UNIAO. Olho Vivo no Dinheiro Público: um guia para os cidadãos garantir os seus direitos. $2^{a}$ edição. Brasília, 2009. Disponível em:

<www.cgu.gov.br.> Acesso em 01 de maio de 2011.

CONTROLADORIA GERAL DA UNIAO. Controle Social: orientações aos cidadãos para participação na gestão pública e exercício do controle social. 2a edição. Brasília, 2010.

Disponível em:

<http://www.cgu.gov.br/Publicacoes/CartilhaOlhoVivo/Arquivos/ControleSocial.pdf.>

Acesso em 01 de maio de 2011.

GIACOMONI, James. Orçamento Público. $8^{\text {a }}$ edição. São Paulo: Atlas, 1998.

GIL, Antonio Carlos. Métodos e Técnicas de Pesquisa Social. $4^{a}$ edição. São Paulo: Atlas, 1995.

GIL, Antonio Carlos. Métodos e Técnicas de Pesquisa Social. $5^{\text {a }}$ edição. São Paulo: Atlas, 1999.

MACHADO JR, J. Teixeira; REIS, Heraldo da Costa. A Lei 4320 comentada: e a lei de responsabilidade fiscal. 31ª edição. Rio de Janeiro: IBAM, 2003. 
MARCONI, Marina de Andrade; LAKATOS, Eva Maria. Metodologia do Trabalho Científico. $6^{\text {a }}$ edição. São Paulo: Atlas, 2001.

MATO GROSSO, Coordenação Regional e Departamentos. Histórico do Campus Universitário de Tangará da Serra. Tangará da Serra: Coordenação Regional, 2008. Disponível em: <http://tangara.unemat.br/documentos/historico_do_campus. pdf> Acesso 24 de outubro de 2011.

MATO GROSSO, Diretoria de Concursos e Vestibulares - COVEST. EDITAL Nº. 003/2011 CONCURSO VESTIBULAR 2012/1 - UNIFICADO. 2011. Disponível em:

$<$ http://concursos.unemat.br/20121/> Acesso 24 de outubro de 2011.

MIRANDA, Carlos Luiz; SILVA, Alan José de Moura; FILHO, José Francisco Ribeiro; SILVA, Lino Martins da. Uma análise sobre a compreensibilidade das informações contábeis governamentais comunicadas pelo Balanço Orçamentário. Brazilia Business Review, Espírito Santo, v 5, no. 3, p. 209-228, set. - dez. 2008

PISCITELLI, Roberto Bocaccio; TIMBÓ, Maria Zulene Farias; ROSA, Maria Berenice. Contabilidade Pública: uma abordagem da administração financeira pública. $8^{a}$ edição. São Paulo: Atlas, 2004.

PLATT NETO, O.A.; CRUZ, F. DA; ENSSLIN, S.R.; ENSSLIN, L. Publicidade e Transparência das Contas Públicas: obrigatoriedade e abrangência desses princípios na administração pública brasileira. $5^{\circ}$ Congresso USP, Controladoria e Contabilidade, 2005.

SECRETARIA DO TESOURO NACIONAL, ESCOLA DE ADMINISTRAÇÃO FAZENDÁRIA. Experiências Recentes de Controle Social sobre o Processo de Orçamentação Pública Municipal no Brasil. 2006. Disponível em:

<http://www.tesouro.fazenda.gov.br/premio_TN/XIPremio/sistemas/2tosiXIPTN/2premio_tos i.pdf.> Acesso em 01 de maio de 2011.

RIBEIRO, Manuella Maia. O uso das tecnologias de informação e comunicação como ferramentas de combate à corrupção do Governo Federal: ComprasNet e o Portal da Transparência. $3^{\circ}$ Concurso de Monografias da Controladoria Geral da União - Controladoria Geral da União, Brasília, DF, 2008. Disponível em:

<http://bvc.cgu.gov.br/handle/123456789/3550> acesso em 20 de outubro de 2011.

SANTOS, Aristeu Jorge dos. Orçamento Público e os Municípios: alguns conceitos de orçamento e suas repercussões na administração pública municipal. Rio Grande do Sul: Escola de Administração da UFRGS, 2001. Disponível em: <http://read.adm.ufrgs.br/edicoes/pdf/artigo_121.pdf > Acesso em 20 de Outubro de 2011.

SILVA, Francisco Carlos da Cruz. Controle Social: Reformando a Administração para a Sociedade. Revista O\&S. Bahia, v. 9, nº. 24, maio-agosto, 2002.

SILVA, Lino Martins da. Contabilidade Governamental: um enfoque administrativo. $7^{\text {a }}$ edição. São Paulo: Atlas, 2004.

VERGARA, Sylvia Constant. Projetos e Relatórios de Pesquisa em Administração. $5^{\text {a }}$ edição. São Paulo: Atlas, 2004. 